\title{
Revised Community of Inquiry Framework: Examining Learning Presence in a Blended Mode of Delivery
}

\author{
Jessica Pool, Gerda Reitsma, and Dirk van den Berg \\ North-West University, South Africa
}

\begin{abstract}
This paper presents a study grounded in the Community of Inquiry (CoI) framework using qualitative content analysis and focus group interviews in an effort to identify aspects of learning presence in a blended learning course. Research has suggested that the CoI framework may need additional emphasis based on the roles of strategic learners in online environments. Consequently, this qualitative study investigated the extent to which learning presence, the fourth presence of the CoI framework, manifested itself in a blended mode of delivery. The specific focus was on learning presence and how it precipitated in a blended-learning environment. Findings from the study indicated that a lack of self-regulation skills, such as time-management, coordination, and management of tasks, influenced the learning presence and required a stronger teaching presence. We concluded that self-regulation skills are supportive of effective learning in a blended learning environment.
\end{abstract}

Keywords: blended learning, community of inquiry, learning presence, self-regulation skills

Pool, J., Reitsma, G., \& van den Berg, D. (2017). Revised community of inquiry framework: Examining learning presence in a blended mode of delivery. Online Learning, 21(3), 153-165 doi: 10.24059/olj.v\%vi\%i.866

\section{Introduction}

Online learning has become part and parcel of higher education, compelling educators to confront existing presuppositions about teaching and learning in higher education. A new landscape has come into existence in education where physical and virtual environments are blended to support learning in university courses (Stacey \& Gerbic, 2008). According to Hadjerrouit (2007), this Blended Learning (BL) approach is becoming the most prominent delivery mechanism in higher education. However, it does present specific challenges for both lecturers to design and students to utilise the best of online and face-to face learning environments.

The Community of Inquiry (CoI) framework is a useful model for describing, explaining and improving online education (Shea \& Bidjerano, 2009). With the exception of authors such as Shea and Bidjerano (2012) and Shea, Hayes, Smith, Vickers, Bidjerano, Pickett, Wilde, GozaCohen and Shoubang (2012), a lack of research regarding the role that self-regulation skills of students as part of learning presence play in a blended learning environment is evident. Research conducted by Shea, Hayes, Vickers, Gozza-Cohen, Uzuner, Metha, Valtcheva and Rangan (2010) points out that previous analysis of data regarding the CoI framework (social, teaching and cognitive presence) contained information that did not fit into the originally established $\mathrm{CoI}$ framework. Social presence refers to the ability to connect with members of a community on a 
personal level, whereas cognitive presence is the process of constructing meaning through collaborative inquiry. Teaching presence is the integrating force that structures and leads the educational process in a constructive, collaborative and sustained manner (Garrison \& Arbaugh, 2007; Garrison \& Cleveland-Innes, 2005; Garrison \& Vaughan, 2008). Shea and Bidjerano (2010) believe that the CoI framework needs to include the roles of strategic learners in online environments. Based on their research, learner self-regulation seems to serve as a basis for a new form of presence within the CoI model, described by Shea and Bidjerano (2010) as learning presence.

Online education requires a greater degree of self-directedness and self-reliance than traditional face-to-face modes of delivery (Dynan, Cate, \& Rhee, 2008; Shea \& Bidjerano, 2012). Despite the many promising features of online and BL instruction, such modes of delivery may have a limited capability to engage students in learning experiences unless students are selfmotivated, active learners who demonstrate strong organizational skills in their learning habits (Banerjee, 2011). Students in online courses face challenges that require persistence and determination, typically required of self-directed learners (Dynan, Cate, \& Rhee, 2008; Shea \& Bidjerano, 2012). Given the on-going expansion of the BL environments Shea and Bidjerano (2012) suggest that we gain insight into successful student self-regulation skills in online environments in order to develop a profile of how students learn online and thus also in a blended environment.

\section{Purpose and Research Question}

Extensive research (Dynan et al., 2008; Hayes, Smith, \& Shea, 2015; Lee, Tsai, Chait, \& Koht, 2014; Shea \& Bidjerano, 2012; Shea et al., 2012) regarding learning presence as an additional construct of the CoI framework has revealed two important gaps that are addressed in this article. Firstly, the existence and establishment of learning presence has been primarily examined in fully online courses and not explicitly in blended learning courses. Secondly, a review of the literature indicated that quantitative methods of research have been the primary method to investigate the manifestation of learning presence in online learning contexts.

The purpose of this article is to report on the manifestation of learning presence in $a$ blended mode of delivery using qualitative analysis, namely document analysis of social media communication (Facebook threads) and focus group interviews. We were guided by the following research questions:

- To what extent did learning presence establish itself in a blended learning environment in a university course for teacher training students?

- How did the students demonstrate self-directed learning skills as part of their learning presence in the blended learning environment?

To answer the research question, the article is structured as follows: The conceptualtheoretical framework that was used as theoretical basis for the research is discussed. Thereafter follow the empirical report, an outline of our findings, a discussion of the findings in view of the conceptual-theoretical framework, and limitations of the study. The findings of the study include implications for lecturers in higher education. 


\section{Conceptual-Theoretical Framework}

The openness of blended learning demands a strong theoretical framework, which informs the integration of face-to-face and online learning. The Community of Inquiry framework is a means to investigate effective online and blended learning environments in higher education (Garrison, Anderson, \& Archer, 2000). This framework is a valid and trustworthy instrument to measure the quality of online learning through its focus on the important presences (social, teaching, cognitive and learning presence) that contribute to the quality of online courses (Shea, Pickett, \& Pelz, 2003; Shea, Sau Li, Swan, \& Pickett, 2005). Lecturers can therefore use it to support the design, implementation and evaluation of effective online and blended learning environments. A cognitivist approach to explore the manifestation of learning presence was utilised in this investigation. The conceptual framing of learning presence by Shea, Hayes, Smith, Vickers, Bidjerano, Gozza-Cohen, Shou Bang, Pickett, Wilde and Tseng (2013) reflects learner self-regulation processes in online educational environments.

The cognitivism learning theory focuses on how students organise and retrieve information as part of learning (Merriam, Caffarella, \& Baumgartner, 2007). Meta-cognition, the learners' understanding of their own learning and learning processes, therefore becomes more significant (Ashwort, Brennan, Egan, Hamilton, \& Saenz, 2004). Cognitivism focuses on learner-centred strategies, as opposed to teacher-centred strategies, so it allows more freedom for students to choose the type of learning that suits them best (Ashwort, Brennan, Egan, Hamilton \& Saenz, 2004). The manifestation of learning presence was investigated to give insight into how students' cognitively thought about and directed their learning experiences in such a blended module.

\section{Learning Presence}

The assumption according to the CoI framework is that higher-order learning is best supported in a community of learners who are engaged in building understanding and critical reflection. The philosophical foundation of the $\mathrm{CoI}$ indicates that certain collaborative interactions create "distance presence", resulting in the emergence of a community of inquiry (Garrison, 2009; Garrison, Cleveland-Innes, \& Shing Fung, 2010). The face-to-face component in blended learning helps to create a community, however this community should be sustained in the online component of the blended course."

Recent research on the CoI framework suggests that not enough focus has been placed on the role, involvement and experience of students in online learning (Shea \& Bidjerano, 2010; Shea et al., 2012). These studies involved further investigation of the CoI framework and the identification of a fourth presence, learning presence, which was not included in the original CoI framework (Bliss \& Lawrence, 2009; Shea \& Bidjerano, 2010; Shea et al., 2010).

Given the self-directed nature of online learning, it is imperative for learners to have selfregulation skills. Zimmerman (2002, p. 65) defines self-regulation as "the self-directive process through which students transform their mental abilities into academic skills". According to Zimmerman, self-regulation refers to self-generated thoughts, feelings and behaviours that are oriented towards attaining goals. Shea and Bidjero (2010) point out that self-regulated online students monitor their time and cognitive strategies, regulate their own study environment, and exercise control over their interactions with peers to maximize learning. The three indicators they associate with self-regulated learning include (Shea et al., 2012): 
- Forethought and planning, wherein students plan, coordinate, and delegate online tasks to themselves and other students

- Monitoring, wherein students check with online classmates for understanding, completion of tasks, and their performance on completed tasks

- Strategy use, wherein students seek, offer, or provide help to complete online activities as well as where students articulate gaps in their knowledge.

Learning presence, according to Shea et al. (2012), refers to students' proactive use of specific processes such as goal setting, strategy selection and personal monitoring of effectiveness. It indicates the exercise of control rather than compliance and passivity. It articulates popular beliefs about the importance of self-direction in online and blended learning environments. Understanding the factors that influence the success of online learning environments has significant implications for designing effective online communities (Shea \& Bidjerano, 2010). The rationale for investigating learning presence is to examine the distinct roles that successful online students may adopt.

\section{Learning Presence as a Construct in the Revised Community of Inquiry Framework}

Results from the study from Shea and Bidjerano (2010) indicated that a clear correlation between constructs of the CoI Framework and self-regulation. According to Knowles (1975):

Self-regulation is a process in which individuals take the initiative, with or without the help of others, in diagnosing their learning needs, formulating learning goals, identifying human and material resources, choosing and implementing appropriate learning strategies, and evaluating learning outcomes. (p18)

Long (1994) added to this students' mental processes for the purpose of gaining knowledge and understanding, solving problems, and developing or strengthening a skill.

These results suggest the addition of learning presence as a new conceptual element to the framework (Shea et al., 2012) (see Figure 1). The revised community of inquiry model (Figure 1) indicates that teaching and social presence are linked to student learning presence. Teaching presence and social presence are important factors to the extent to which students believe that they achieve effective learning, and the effort they spend depends partly on their sense of selfdirectedness. Based on these studies, learning presence can be accomplished via expanded teaching presence. Teaching presence contributes to the effectiveness of online learning through the development of self-regulation skills in learners who are meta-cognitively, motivationally and behaviourally active participants in their own learning process (Shea \& Bidjerano, 2012). 


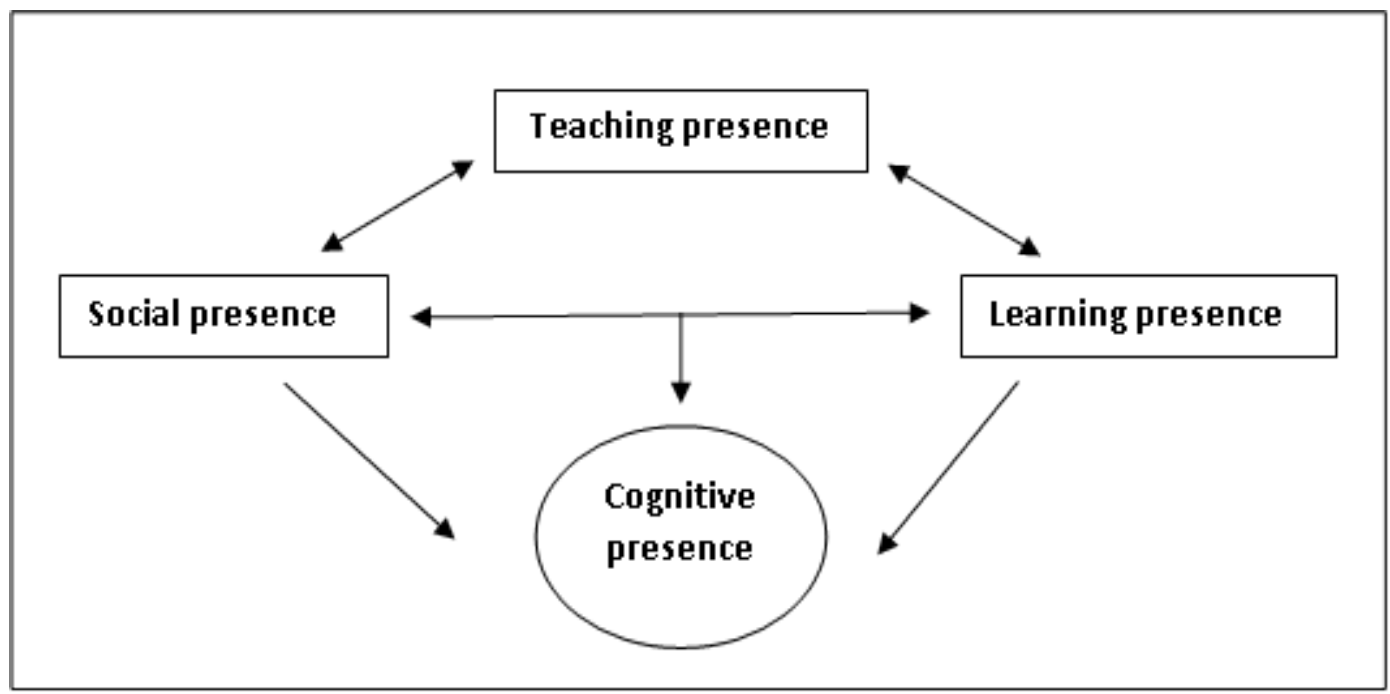

Figure 1: Revised Community of Inquiry model (Shea et al., 2012)

\section{Relationship Between the Presences in the Revised Community of Inquiry Framework}

The CoI Framework outlines the processes required to enable knowledge construction in online environments through the development of teaching, social and cognitive presence. Consistent with previous research,(Garrison \& Vaughan, 2008) the three presences (social, cognitive and teaching) are interconnected and have an influence on one another. The interconnectedness between the three presences supports the finding that teaching presence has a regulatory and mediating role and that it merges all elements in a balanced and purposeful relationship. Teaching presence is essential in establishing a sense of social presence by engendering an atmosphere of meaningful communication, cohesive discourse and personal connections. It sets the stage for purposeful discourse and reflective learning processes. In this sense, social presence is a mediating factor that provides context for the educational process. The relationship between teaching presence and cognitive presence becomes clear when students are assigned engaging tasks requiring them to move through the phases of cognitive presence (triggering event, exploration, integration and resolution) as elements of practical inquiry. Once students are engaged, teaching presence has a significant influence in facilitating and directing student learning, which has shown to be crucial in reaching resolution phase and thus achieve a successful learning experience(Garrison \& Vaughan, 2008). We are of the opinion that successful learning will only happen if the lecturer actively and effectively structures the course in such a way that the direct instruction and facilitation of discourse leads to higher order learning, which then would result in practical inquiry (cognitive presence). Learning presence represents an important mediator of the links between teaching, social and cognitive presence and therefore aspects of learning presence should not be considered separate from the CoI. 


\section{Research Context}

\section{Methods}

The context for this study was a fourth year methodology course for final year teacher training students. Originally, the course was a full-time on-campus course delivered by means of traditional face-to-face interaction, with students engaging with the largest component of the course content during structured face-to-face contact sessions. These contact sessions took the form of two one-hour contact sessions per week, with all sessions being formally planned, structured and facilitated by the lecturer, although with active student participation during the sessions

\section{Research Design}

A design-based research approach (Amiel \& Reeves, 2008; Anderson \& Shattuck, 2012) was followed throughout the redesigning process to develop and establish communities of inquiry in the blended learning course. Part of the design-based research involved descriptive qualitative research, of which we report on in this study.

\section{Participants}

The target population for this study was a group of teacher training students $(N=58)$ enrolled as full-time students at the Faculty of Educational Sciences at a comprehensive university in South Africa. These students came from two different specialisation areas: Computer-aided Technology (CAT) and Learning Area Technology (TE - Design and Technology). Informed consent was obtained from each student before the data was used for this study. Ethical clearance was received from the university's ethical committee.

\section{Data Collection and Analysis}

Data collection started with a semi-structured interview with the lecturer responsible for the module. The purpose of the interview was to gain an understanding of the manner in which the face-to-face module was presented. The contact-based, face-to-face course was re-designed into a blended learning course at the start of the semester. The researcher, in collaboration with the lecturer and campus academic support staff, moved a significant portion of the learning activities to the online environment. Guidelines offered by Garrison and Vaughan (2008) for establishing a community of inquiry were followed during the design and implementation of the course. These guidelines included the sustainment of a community through expression of group cohesion, and the development of collaborative relationships where students are supported to assume responsibility for their learning,

During the course students were required to communicate on a Facebook page which was specifically created as an online platform. The nature of the threads included formal and informal communication between the lecturer and students as well as students with each other. The Facebook threads were collected throughout the course with the purpose to inform the researchers on the establishment of Communities of Inquiry as well as to guide further refinements to the blended learning course. The threads were analysed as a form of document analysis which is a qualitative research method involving the interpretation of a variety of relevant documents to give voice and meaning to a central topic (Fraenkel \& Wallen, 2003). In addition, 2 focus group interviews with 7 participants per group were conducted near the end of the semester to provide additional information on their participation and collaboration in the blended course. 
The interview schedule consisted of 14 questions of which question 1-4 addressed the teaching presence, 5-9 addressed social presence and question 10-14 addressed cognitive presence. The focus group interviews, facilitated by the researcher, were audio recorded and lasted between 30 and 60 minutes. The transcribed data were checked for accuracy by an independent researcher (Merriam, 2009). Both sets of data (interviews and Facebook threads) were analysed using priori codes, derived from the literature and posteriori codes that emerged from the data were utilised (Creswell \& Piano, 2011). During the data analysis the researchers systematically made sense of the data through selecting, categorizing, comparing, synthesizing and interpreting the data. Students participated voluntary and with consent. A co-researcher co-coded the interviews to verify dependability, a form of reliability in qualitative data coding (Delport \& De Vos, 2011).

\section{Discussion}

Although learning presence was not tested in the original CoI survey, we wanted to investigate the extent to which learning presence manifested itself in this blended module using qualitative research methods. The reason for examining learning presence is to shed light on the distinct roles that successful online students may adopt in an online learning environment.

The data showed evidence of learning presence in the way that students communicated with each other, took responsibility for own learning and organising their learning activities. Learning presence is associated with self-regulation skills which include time-management, selfdiscipline, setting goals, self-reliance and dividing up tasks (Banerjee, 2011; Brunner, Brendenlier, Stoter, Hohlfeld, \& Von Ossietzky, 2015). Similar concepts for learning presence emerged during the coding process of the qualitative data, including time management, self-discipline, task driven, setting goals and segmenting tasks. What emerged from the data was that students struggled with self-regulation requirements expected of them in a blended learning environment, making the learning process more challenging for them.

In the online learning environment, students missed the personal attention of the lecturer that is typically part of the face-to-face environment. Most students mentioned that they felt lost in the online environment where they had to use self-regulation measures such as forethought and planning, coordinating and delegating online tasks to themselves and other students, as can be seen from these student comments:

Sandy: I missed the personal aspect of the lecturer because we were not used to completing most activities online. The online environment caused frustration because we thought we had to do everything by ourselves and we are not used to doing everything by ourselves. For four years we only had contact lessons and saw the lecturer face-to-face and now everything feels different.

Bob: I would open my phone and then close it to go back later to the group discussion, and then when I go back later it is too late to raise my opinion, because by then the other group members already decided what must be done.

An important aspect of self-regulation is time management. A number of students reported that time management was a very big challenge for them and, as is evident from the responses below, students lack these skills: 
Susan: So, I believe time management was the problem. I feel we always had the learning management system (eFundi) with our other subjects. The problem was just time management.

Sandy: I was very confused and it was very challenging in terms of time management. Jennifer: Your time management had to be a hundred percent accurate.

Jennifer: We go on eFundi then we see there that an assignment or something must be submitted now, but then it is eleven o'clock and I see it had to happen [be submitted] at twelve o'clock.

Bob: Time management is a big factor in a blended learning course.

Coordinating activities and dividing tasks were another challenging requirement for the students. Half of the students reported that getting their groups together were time consuming and frustrating. Segmenting tasks is also associated with time-management skills and, therefore, learning presence. Responses from students explain their difficulties:

Mary: The online component was not the problem, but to get portions of the work to other members of the group. That was a problem.

Stephanie: I think the arrangement of group activities was a challenge. Groups had to get together...it often fell during class time when we have other classes. Not everyone has the same classes, so they can use that time and now you can't join them. Then you arrive afterwards and then they have finished working. So it was kind of difficult because the normal, scheduled period for the subject was not sufficient to do a group assignment.

Suzie: Sometimes you arrange for the group to get together for example, meet at eleven; then it happens that only three or two of the five shows up and then arranging group work was really difficult.

Taylor: I spent most of the time on my phone making arrangements with other group members and then they just don't show up.

In contrast, some students reported on the successful coordination, dividing of tasks and arrangement of group activities through the use of the LMS:

Bob: We made plenty use of e-mails to divide the work. Each one sends the part he did back and then the other one just check if it is correct. Then it gets sent to the group leader and he/she submits it.

Student-student communication and coordination through email conversations were further evident in these responses:

Jess: Can you mail me your group work to this email address... then I will email ours to you to send to the rest of the group.

Bella: Fine with us. You can mail us your comments then we can start working on the mind map.

One student pointed out that some of the frustration and uncertainty on how to complete activities were due to the lack of self-discipline. Although support in the form of scheduled contact sessions and online consultation hours was provided to students to be able to function in the online environment, not all students made effective use of it. 
Self-discipline is an important skill needed to monitor one's use of the guidance provided. Students could experience the personal one-on-one attention and guidance provided by the lecturer during the contact sessions, but attending contact sessions in a blended learning module is dependent on the students' self-discipline and self-regulation, as is evident from the following student's remark:

Tino: You can also deduce, from the students' comments in the online environment, when students did not attend the scheduled contact lectures. Many students did not understand what to do because they weren't in class. The help [assistance] provided in the contact lectures, along with the online instructions, made it really easy to complete activities successfully.

Analysis of the Facebook threads, showed that students did engage in strategic efforts such as taskdriven skills through the setting of goals, as the following extract from the Facebook page illustrates:

Anna: Hi all, we need to get together to discuss the question that need to be completed for the Tuesday online session. When do you want to get together and where?

Margaret: Why can't we discuss it on Facebook?

Anna: Go and read under week 2 period one in the study guide and tell me what you think.

Botha: Hi all, we may have to get together on Sunday or Monday somewhere to finish the group questions.

Anna: Yes definitely. Preferably Monday morning early, if you can because it needs to be submitted at 2 .

Anna: Okay let's get together at 9. Outside the education library.

Margaret: Fine with me

Margaret: Hi all, I have submitted the answer. It looks good!

The online component in this blended learning module required a greater degree of selfdirectedness and self-reliance for students to take responsibility for their own learning. The analysis of the Facebook threads indicated that most of the students struggled to take responsibility for their own work and learning, as is evident from the following students' remarks:

Carrie: No one has ever shown me how to use the chat function on eFundi. So I don't know how the chat room works on eFundi and that is why I didn't even bother to take a look.

Bob: I don't even have Facebook, so I missed quite a bit.

Taylor: ... then they just don't show up. It was a bit frustrating, because not everyone. wants to produce work of the same quality. For some it is important; for others it is not important. This made the group work a bit frustrating.

Learners' self-regulation in online environments should be examined given the online, social and self-directed nature of online learning. This study indicated that the presence of the lecturer is still very important for the students. Banerjee (2011) reported the same findings where he wrote that the majority of students still expect to meet regularly in the classroom environment for lecture based classes. The lack of self-discipline skills in utilising the two environments typical of blended learning effectively was consistent with previous research (Banerjee, 2011; Shea \& Bidjerano, 
2012; Traver, Volchok, Bidjerano, \& Shea, 2014) and also evident in the findings of this study. Evident from the literature (Shea et al., 2012) as well as the findings from this study indicates that learning in an online environment requires specific time- and task-management skill which students struggled with . Banerjee (2011) reported on similar findings. However, there were evidence in the Facebook threads of students engaging to some extent in strategic self-regulation, such as setting goals and being task driven.

\section{Conclusion}

In this article, learning presence, a fourth presence in the CoI framework conceptualised by Shea (2010), as it emerged in a blended learning course for teacher training students was investigated through qualitative research and described. We focussed on self-regulated learning as a component of learning presence.

Results indicate that learning presence was established in this blended learning course, but it was influenced by the self-regulation skills of the students. The lack of self-regulation, including time-management skills, and the ineffective coordination and management of tasks were identified as challenges experienced by students in the online part of the blended learning. It proved imperative for students to have self-regulation skills in a blended learning environment.

The lack of self-regulation skills made the role of the teacher more important. We therefore concluded that teaching presence plays an important role in blended learning, especially when students are exposed to blended learning for the first time, causing them to need initial support and guidance. As their self-regulation skills improve, learning presence may become more significant and teaching presence may play a less significant role.

\section{Limitations}

In this study, only the students' experiences were reported. The lecturer's viewpoint on how students engaged with the course in a blended learning environment will provide additional enriching results.

The data were also limited to what was available to the researchers on Facebook and the focus group interviews. Data from students who did not participate in the Facebook discussions or in the focus group interviews were not included and may have provided additional meaningful evidence. 


\section{References}

Amiel, T., \& Reeves, C. R. (2008). Design-based research and educational technology: Rethink technology and the research agenda. Educational Technology \& Society, 11(4), 29-40.

Anderson, T., \& Shattuck, K. (2012). Desig-based research: A decade of progress in educational research? Educational Research, 41(1), 16-25.

Ashwort, F., Brennan, G., Egan, K., Hamilton, R., \& Saenz, O. (2004). Learning theories and higher education. School of Electrical and Electronic Engineering, 3(2).

Banerjee, G. (2011). Blended environments: Learning effectiveness and student satisfaction at a small college transition. Journal of Asynchronous Learning Networks, 15(1), 8-19.

Bliss, C. A., \& Lawrence, B. (2009). From posts to patterns: A metric to characterize discussion board activity in online classes. Journal of Asynchronous Learning Networks, 13(2), 15 32.

Brunner, S., Brendenlier, S., Stoter, J., Hohlfeld, G., \& Von Ossietzky, C. (2015). "Are they ready?" Self-directed learning readiness and acceptance of e-learning tools: Comparing non-traditional and traditional students. Retrieved from http://eurodl.org/materials/special/2015/Brunner et al.htm

Creswell, J. W., \& Piano, C. L. (2011). Mixing and conducting mixed methods research. London: SAGE Publications.

Delport, C. S. L., \& De Vos, A. S. (2011). Professional research and professional practice. In A. S. De Vos, H. Strydom, C. B. Fouche \& C. S. L. Delport (Eds.), Research at grassroots for the social sciences and human service professions (Vol. 4th). Pretoria: Van Schaik.

Dynan, L., Cate, T., \& Rhee, K. (2008). The impact of learning structure on students' readiness for self-directed learning. Journal of Education for Business, 84(2), 96-100.

Fraenkel, J. R., \& Wallen, N. E. (2003). How to design and evaluate research in education (5th ed.). New York: McGraw-Hill.

Garrison, D. R. (2009). Implications of online learning for the conceptual development and practice of distance education. Journal of Distance Education, 23(2), 93-104.

Garrison, D. R., Anderson, T., \& Archer, W. (2000). Critical inquirty in a text-based environment: Computer referencing in higher education. Internet and Higher Education, 2(2-3), 1-19.

Garrison, D. R., \& Arbaugh, J. B. (2007). Research the community of inquiry framework: Review, issues, and future directions. Internet and Higher Education, 10, 157-172. 
Garrison, D. R., \& Cleveland-Innes, M. (2005). Facilitating cognitive presence in online learning: Interaction is not enough. The American Journal of Distance Education, 19(3), 133-148.

Garrison, D. R., Cleveland-Innes, M., \& Shing Fung, T. (2010). Exploring casual relationships among teaching, cognitive and social presence: Student perceptions of the community of inquiry framework. Internet and Higher Education, 13, 31-36.

Garrison, D. R., \& Vaughan, N. D. (2008). Blended learning in higher education: Framework, principles, and guidelines. San Francisco: Jossey-Bass.

Hadjerrouit, S. (2007). A blended elarning model in Java programming: A design-based approach. Proceedings of the Computer Science and IT Education Conference, 283-308.

Hayes, S., Smith, S. U., \& Shea, P. (2015). Expanding learning presence to account for the direction of regulative intent: Self-, co- and shared regulation in online learning. Journal of Online Learning, 19(3), 1-19.

Knowles, M. S. (1975). Self-directed learning: A guide for learners and teachers. New York: Association Press.

Lee, K., Tsai, T., Chait, C. S., \& Koht, J. H. L. (2014). Students' perceptions of self-directed learning and collaborative learning with and without technology. Journal of Computer Assisted Learning, 30, 425-437.

Long, H. B. (1994). Resources related to overcoming resistance to self-direction in learning. New Directions for Adult and Continuing Education, 64, 13-21.

Merriam, S., Caffarella, R. S., \& Baumgartner, L. M. (2007). Learning in adulthood: A comprehensive guide (3rd ed.). San Francisco: John Wiley \& Sons/Jossey-Bass.

Shea, P., \& Bidjerano, T. (2009). Commuity of inquiry as a theoretical framework to foster "epistemic engagement" and "cognitive presence" in online education. Computers \& Education, 52, 543-553.

Shea, P., \& Bidjerano, T. (2010). Learning presence: Towards a theory of self-efficacy, self regulation, and the development of communities of inquiry in online and blended learning. Computers \& Education, 55, 1721-1731.

Shea, P., \& Bidjerano, T. (2012). Learning presence as a moderator in the community of inquiry model. Computers \& Education, 59, 316-326.

Shea, P., Hayes, S., Smith, S. U., Vickers, J., Bidjerano, T., Pickett, A., . . Shoubang, J. (2012). Learning presence: Additional research on a new conceptual element within the Community of Inquiry (CoI) Framework. Internet and Higher Education, 15, 89-95. 
Shea, P., Hayes, S., Vickers, J., Gozza-Cohen, M., Uzuner, S., Mehta, R., . . Rangan, P. (2010). A rexamination of the community of inquiry framework: Social network and content analysis. The Internet and Higher Education, 13(1-2), 10-21.

Shea, P., Pickett, A., \& Pelz, W. (2003). A follow-up investigation fo "teaching presence" in the Suny learning network. Journal of Asynchronous Learning Networks, 7(2), 61-80.

Shea, P., Sau Li, C., Swan, K., \& Pickett, A. (2005). Developing learning community in online asynchronous college courses: The role of teaching presence. Journal of Asynchronous Learning Networks, 9(4), 59-82.

Stacey, E., \& Gerbic, P. (2008). Success factors for blended learning. The 26th Annual Cofererence of the Australasian Society for Computers in Learning in Tersiary Education (ascilite) Anual Acilite Conference, 964-968.

Traver, A. E., Volchok, E., Bidjerano, T., \& Shea, P. (2014). Correlating community college students' perceptions of of community of inquiry presences with their completion of blended courses. Internet and Higher Education, 20, 1-9.

Zimmerman, J. B. (2002). Becoming a self-regulated learner: An overwiew. Theory in Practice, 41(2), 65-70. 